\title{
Application method of fourier transform infrared (FTIR) combined with chemometrics for analysis of rat meat (Rattus diardi) in meatballs beef
}

\section{Aplikasi metode fourier transform infrared (FTIR) dikombinasikan dengan kemometrika untuk analisis daging tikus rumah (Rattus diardi) dalam bakso daging sapi}

\author{
Any Guntarti*, Seshilia Rarasati Prativi \\ Fakultas Farmasi Universitas Ahmad Dahlan \\ Jl. Prof. Dr. Soepomo,S.H., Janturan, Yogyakarta
}

\begin{abstract}
ABSTRAK
Pemalsuan produk makanan mulai menjadi masalah baru disekitar masyarakat Indonesia. Masalah yang banyak mendapat perhatian khusus terutama adanya kekhawatiran tercemarnya produk makanan oleh daging yang bersifat non-halal. Salah satunya daging tikus rumah pada produk olahan makanan bakso. Penelitian ini diharapkan dapat menjadi salah satu dasar untuk tercapainya penjaminan produk non-halal terhadap produk bakso sapi, agar tidak tercemar daging tikus rumah yang non-halal. Studi penggunaan spektrofotometri Fourier Transform Inframerah (FTIR) yang dikombinasikan dengan kemometrika dapat digunakan untuk mengidentifikasi adanya daging tikus rumah pada bakso sapi secara kualitatif dan kuantitatif. Sampel bakso dibuat dengan menyiapkan daging tikus rumah murni dan daging sapi murni. Sampel kalibrasi disiapkan dengan membuat bakso yang mengandung konsentrasi daging tikus rumah-daging sapi dengan variasi sebesar $0 \%, 25 \%, 35 \%, 65 \%, 75 \%$, dan $100 \%$ daging tikus rumah dalam adonan bakso sapi. Disiapkan sampel validasi dengan konsentrasi sama seperti pada sampel kalibrasi dan 5 sampel bakso yang beredar dipasaran. Lemak sapi dan lemak tikus rumah yang terkandung pada bakso diekstraksi dengan alat Soxhlet pada suhu $\leq 70^{\circ} \mathrm{C}$ selama 7 jam dengan pelarut $n$-heksan. Analisis kuantitatif dilakukan pada bilangan gelombang $750-1600 \mathrm{~cm}^{-1}$ dengan menggunakan teknik analisis multivariat partial least square (PLS) dan analisis kualitatif principal component analysis (PCA). Hasil model kalibrasi dengan $\mathrm{y}=0,9720 \mathrm{x}+1,580$, nilai koefisien determinasi $\left(\mathrm{R}^{2}\right)=$ 0,9941 , dan nilai root mean square error of calibration (RMSEC) sebesar 1,63\%. Model validasi dengan, nilai root mean square error of cross validation (RMSECV) sebesar 1,79\%, dan nilai root mean square error of prediction (RMSEP) sebesar 2,60\%. Lemak sapi dan lemak tikus rumah berhasil dikelompokkan dengan menggunakan kemometrika PCA.
\end{abstract}

Kata kunci: bakso sapi, daging tikus rumah, Spektroskopi FTIR, Partial Least Square (PLS), Principal Component Analysis (PCA), pemalsuan

\footnotetext{
Penulis korespondesi:

Any Guntarti

Universitas Ahmad Dahlan

J1. Prof. Dr. Soepomo,S.H., Janturan, Yogyakarta

Email: any_guntarti@yahoo.co.id
} 


\begin{abstract}
Counterfeit food products are starting to become a new problem around the people of Indonesia. Problems that are getting special attention especially the concern of contamination of food products by non-halal meat . For example rat meat on meatballs. This research is expected to be one of the basis for the guarantee of non-halal meatballs products. The study of Fourier Transform Infrared spectrophotometry (FTIR) combined with chemometrics can be used to identify the presence of rat meat in meatballs qualitatively and quantitatively. Samples of meatballs are made by preparing pure rat and pure beef meat. The calibration samples were prepared by making meatballs containing beef - rat with variations of $0 \%, 25 \%, 35 \%, 65 \%, 75 \%$, and $100 \%$ rat meat in dough meatballs. Validation samples were prepared from a number of meatballs prepared in the laboratory containing rat meat in a certain concentration and 5 samples of meatballs in the market. Cow and rat fat contained in meatballs were extracted with Soxhlet at $\leq 70^{\circ} \mathrm{C}$ for 7 hours with nhexane solvent. Quantitative analysis was performed on wave number $750-1600 \mathrm{~cm}^{-1}$ using multivariate partial least square (PLS) and qualitative analysis with principal component analysis (PCA). Result of calibration model with $\mathrm{y}=0.9720 \mathrm{x}+1.580$, coefficient of determination $(\mathrm{R} 2)=$ 0.9941, and root mean square error of calibration (RMSEC) value equal to $1.63 \%$. The validation model with the root mean square error of cross validation (RMSECV) is $1.79 \%$, and the root mean square error of prediction (RMSEP) is $2.60 \%$. By using PCA, the grouping of cow and rat fat in the meatball successfully done.
\end{abstract}

Keywords : meatball, rat meat, FTIR spectroscopy, Partial Least Square (PLS), Principal Component Analysis (PCA)

\title{
PENDAHULUAN
}

Topik terkait makanan halal merupakan salah satu topik yang menarik untuk dibahas dan diteliti, karena makanan merupakan kebutuhan dasar untuk kesejahteraan manusia. Dengan kemajuan ilmu pengetahuan dan teknologi modern, mulai ada produk makanan yang dicampur dengan bahan non-halal (Van der Spiegel et al., 2012; Schieber, 2008). Sebagian besar komponen non-halal yang ditemukan di pasar adalah daging babi, lemak babi, gelatin babi, dan produk-produk berbasis babi (Maryam et al., 2016; Rahmawati et al., 2016; Sudjadi et al., 2016). Bahan-bahan yang terdapat dalam produk makanan, farmasi atau produk kosmetika dapat bersifat diperbolehkan untuk dikonsumsi secara hukum Islam (halal) atau dilarang dikonsumsi menurut hukum Islam (haram) (Mursyidi, 2013; Raraswati et al., 2013).

Salah satu produk makanan yang favorit dikonsumsi masyarakat Indonesia adalah bakso. Bakso biasanya dibuat daging sapi yang dicampur dengan tepung dan bumbu-bumbu tertentu. Beberapa negara memiliki nama sendiri untuk bakso, yaitu Bakso (Indonesia) (Rohman et al., 2011). Bebola (Malaysia), Nem nuong (Vietnam), Kofta (India), Konigsberger klopse (Jerman), Koefte (Turki), Kung-Wan (Taiwan dan Cina), dan Polpette (Italia) (Huda et al., 2009). Harga daging sapi di pasaran yang relatif lebih mahal dibandingkan dengan daging lain membuat beberapa pedagang berusaha menyiasati harga produksi pembuatan bakso sapi (Julaikha, 2013). Pencampuran daging sapi dengan daging lain dalam pembuatan bakso dirasa menjadi solusi yang efektif untuk menurunkan harga produksi pembuatan bakso, dan kasus yang paling ekstrim adalah mencampurnya dengan daging tikus rumah.

Spektrofotometri FTIR merupakan kajian tentang interaksi antara radiasi elektromagnetik dengan materi (sampel). Saat ini dengan perkembangan transformasi Fourier, spektroskopi FTIR digunakan secara luas dalam bidang farmasi, makanan, lingkungan dan sebagainya (Che Man et al., 2010). Spektrofotometri FTIR telah banyak dikembangkan untuk analisis derivat babi (Guillén and Cabo, 1997), analisis kualitatif atau kuantitatif komponen non-halal dalam berbagai produk makanan seperti kue dan coklat (Che Man et al., 2005; Syahariza et al., 2005), untuk analisis 
berbagai minyak nabati (Rohman and Man, $2010^{\mathrm{b}}$ ), analisis pemalsuan bakso sapi dengan daging babi (Rohman et al., 2011).

Penelitian ini bertujuan untuk mengetahui profil spektra dan pengelompokkan lemak daging sapi dan daging tikus rumah dengan instrumen FTIR. Selain itu juga untuk mengetahui ada tidaknya cemaran daging tikus rumah pada produk bakso daging sapi yang ada di pasaran dengan instrumen FTIR yang dikombinasikan dengan kemometrika. Hasil penelitian ini dapat digunakan sebagai penelitian pendahuluan untuk mengetahui kandungan non-halal dalam produk makanan.

\section{METODE PENELITIAN}

\section{Alat dan Bahan}

Bahan yang digunakan dalam penelitian ini adalah lemak dari bakso daging sapi dan bakso daging tikus rumah, n-heksana, $\mathrm{Na}_{2} \mathrm{SO}_{4}$ anhidrat dan bakso sampel pasaran. Instrumen yang digunakan adalah Spektrofotometer FTIR ABB MB 3000 (Kanada) yang dilengkapi dengan lempeng kristal ZnSe, detektor deuterated triglycine sulfate (DTGS) dengan teknik penanganan sampel attenuated total reflectance (ATR), serta pemecah berkas sinar Germanium pada substrat $\mathrm{KBr}$. Tetesan minyak ditempatkan pada kristal ATR pada suhu terkendali $\left(20^{\circ} \mathrm{C}\right)$. Pengukuran dilakukan pada 32 scan, daya pisah (resolusi) $4 \mathrm{~cm}^{-1}$, alat-alat gelas, Soxhlet.

\section{Jalannya Penelitian \\ Pengadaan daging}

Bahan yang digunakan adalah daging tikus rumah yang diperoleh dari rumah warga Maguwoharjo, Sleman, Daerah Istimewa Yogyakarta dan daging sapi yang di peroleh dari Pasar Gedong Kuning, Kota gede, Daerah Istimewa Yogyakarta. Bumbu-bumbuan, dan bahan tambahan lainnya untuk pembuatan bakso dibeli di supermarket di sekitar kampus 3 Universitas Ahmad Dahlan, Daerah Istimewa Yogyakarta. yang diolah menjadi bakso. Sampel bakso pasaran dari pedagang kaki lima yang ada di Yogyakarta.

\section{Prosedur}

Sampel bakso dibuat dengan menyiapkan daging tikus rumah murni dan daging sapi murni. Sampel kalibrasi disiapkan dengan membuat bakso yang mengandung konsentrasi daging tikus rumah-daging sapi variasi konsentrasi daging sapi dan daging tikus rumah untuk dalam pembuatan produk bakso, yaitu sebesar $0 \%, 25 \%, 35 \%, 65 \%, 75 \%$, dan $100 \%$ daging tikus rumah dalam adonan bakso sapi Sampel validasi disiapkan dari sejumlah bakso yang disiapkan di laboratorium yang mengandung daging tikus rumah dalam konsentrasi tertentu. Pembuatan bakso dilakukan sebagaimana yang dilakukan Purnomo dan Rahardiyan (2008). Bakso disiapkan dengan mencampurkan $90 \%$ daging yang telah digerus halus (tikus rumah, tikus rumah-sapi, sapi) dengan gandum $10 \%$, kemudian dicampur dengan garam, bawang putih, dan merica yang umum digunakan pada pembuatan bakso. Formula selanjutnya dibentuk seukuran bola pingpong dan selanjutnya direbus ke dalam air mendidih selama 10 menit. Komposisi campuran daging tikus rumah dan daging sapi dapat dilihat pada Tabel I.

Tabel I. Formula bakso campuran daging sapi dan tikus rumah

\begin{tabular}{lccc}
\hline \multicolumn{1}{c}{ Konsentrasi } & $\begin{array}{c}\text { Daging Sapi } \\
\text { (gram) }\end{array}$ & $\begin{array}{c}\text { Daging Tikus } \\
\text { Rumah (gram) }\end{array}$ & $\begin{array}{c}\text { Bumbu } \\
\text { (gram) }\end{array}$ \\
\hline Sapi 100\% & 45,00 & - & 5,00 \\
Tikus Rumah 100\% & - & 45,00 & 5,00 \\
Tikus Rumah 75\% & 33,75 & 11,25 & 5,00 \\
Tikus Rumah 65\% & 29,25 & 15,75 & 5,00 \\
Tikus Rumah 35\% & 15,75 & 29,25 & 5,00 \\
Tikus Rumah 25\% & 11,25 & 33,75 & 5,00 \\
\hline
\end{tabular}




\section{Ekstraksi lemak}

Bakso dengan variasi konsentrasi dan bakso produk pasaran yang telah dicincang atau dihaluskan, dimasukkan kedalam kertas saring dan diletakkan ke dalam alat Soxhlet, dilakukan pada suhu $\leq 70^{\circ} \mathrm{C}$ selama $\leq 7$ jam. Ekstrak lemak diperoleh ditambahkan $\mathrm{Na}_{2} \mathrm{SO}_{4}$ anhidrat. Lemak yang diperoleh dimasukkan dalam appendorf, disimpan di dalam almari es.

\section{Analisis Data}

Data hasil spektrum FTIR yang diperoleh diolah dan dianalisis dengan kombinasi kemometrika multivarias PLS dan PCA menggunakan software Horizon $\mathrm{MB}^{\mathrm{TM}}$ dalam perangkat komputer spektrofotometri FTIR.

\section{HASIL DAN PEMBAHASAN}

\section{Ekstraksi lemak}

Pembuatan bakso dilakukan sebagaimana dalam Purnomo and Rahardiyan (2008). Ekstraksi lemak dilakukan menggunakan Soxhlet, menggunakan pelarut $n$-heksan yang diharapkan mampu mengekstraksi seluruh lemak yang berada didalam adonan bakso campuran daging tikus rumah dan daging sapi. Pelarut $n$-heksan sangat cocok digunakan dalam ekstraksi lemak pada adonan bakso, karena $n$-heksan bersifat non-polar sama seperti lemak yang juga bersifat non-polar. Penambahkan $\mathrm{Na}_{2} \mathrm{SO}_{4}$ anhidrat untuk menghilangkan kandungan air dalam ekstrak lemak tersebut. Penguapan pelarut $n$-heksan dilakukan di dalam lemari asam dalam waktu $\leq 24$ jam.

\section{Analisis lemak dengan spektrofotometri FTIR}

Spektroskopi inframerah merupakan salah satu jenis spektroskopi vibrasional (Rohman and Che Man, 2012). Molekul penyusun lemak saat dianalisis menggunakan spektrofotometer FTIR akan menyerap energi radiasi inframerah pada bilangan gelombang tertentu, dan akan terjadi getaran (vibrasi). Selanjutnya molekul akan mengalami perubahan momen dipol ketika vibrasi. Seluruh spektra IR direkam pada daerah 4000 sampai $650 \mathrm{~cm}^{-1}$.

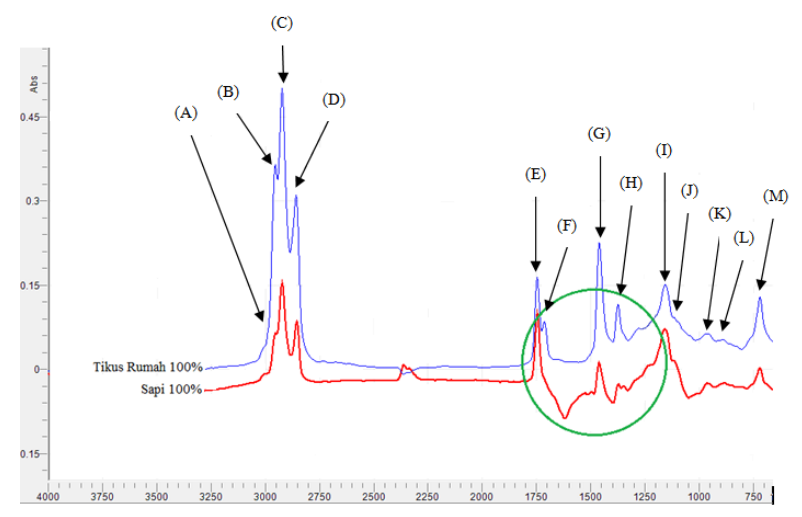

Gambar 1. Spektra FTIR lemak bakso Sapi $100 \%$ dan lemak Tikus Rumah $100 \%$. Lingkaran hijau menggambarkan pita diferensiasi antara lemak sapi dan lemak tikus rumah

Pada Gambar 1, sekilas tidak terdapat perbedaan kedua spektra IR antara lemak sapi dan lemak tikus rumah. Karena sebenarnya kedua lemak ini memiliki struktur asam lemak yang sama yaitu trigliserida. Optimasi bilangan gelombang diperoleh daerah $1600-750 \mathrm{~cm}^{-1}$. Optimasi bilangan gelombang untuk melihat daerah gugus fungsi yang terdapat pada masing-masing bakso lemak sapi dan bakso lemak tikus rumah. Hasil pengukuran spektra disajikan pada Tabel II.

Pada puncak $3004 \mathrm{~cm}^{-1}$ (A) dapat terjadi karena disebabkan adanya perenggangan $-\mathrm{CH}$ vinylic. Vibrasi ulur asimetris gugus metil $\left(\mathrm{CH}_{3^{-}}\right)$terlihat pada frekuensi $2954 \mathrm{~cm}^{-1}(\mathrm{~B})$, dan vibrasi 
ulur asimetris dan simetris dari metilen $\left(-\mathrm{CH}_{2}-\right)$ juga dapat terlihat pada frekuensi $2923 \mathrm{~cm}^{-1}$ (C) dan $2854 \mathrm{~cm}^{-1}$ (D). Dari masing-masing kelompok metilen dan metil dapat pula diamati pada bilangan gelombang $1461 \mathrm{~cm}^{-1}(\mathrm{G})$, ini disebabkan karena adanya getaran tekuk dari mereka. Pada bilangan gelombang $1747 \mathrm{~cm}^{-1}(\mathrm{E})$ terdapat puncak yang menunjukkan gugus karbonil $(\mathrm{C}=\mathrm{O})$ dari ikatan ester triasilgliserol, puncak ini terdapat dalam lemak sapi dan juga lemak tikus rumah. Bilangan puncak ini muncul karena struktur dasar dari asam lemak adalah triasilgliserol yang didalamnya terdapat tiga buah gugus yaitu gugus karbonil ester.

Tabel II. Gugus fungsi dan model vibrasi IR lemak sapi dan lemak tikus rumah

\begin{tabular}{lll}
\hline \multicolumn{1}{c}{ Kode } & \multicolumn{1}{c}{$\begin{array}{c}\text { Bilangan gelombang } \\
\left(\mathbf{c m}^{-1}\right)\end{array}$} & Vibrasi gugus fungsi \\
\hline (A) & 3004 & Cis C=CH uluran \\
$(\mathrm{B})$ & 2954 & Vibrasi ulur asimetris gugus metil $\left(-\mathrm{CH}_{3}\right)$ \\
$(\mathrm{C})$ dan (D) & 2923 dan 2854 & Vibrasi ulur asimetris dan simetris gugus metilen $\left(-\mathrm{CH}_{2}\right)$ \\
$(\mathrm{E})$ & 1747 & Gugus fungsi karbonil $(\mathrm{C}=\mathrm{O})$ dari ikatan ester triasilgliserol \\
$(\mathrm{F})$ & 1712 & $\mathrm{C}=\mathrm{O}$ ulur asam karboksilat \\
$(\mathrm{G})$ & 1461 & Vibrasi tekuk dari gugus $\mathrm{CH}_{2}$ dan $\mathrm{CH}_{3}$ alifatik \\
$(\mathrm{H})$ & 1377 & Vibrasi tekuk simetris gugus $\mathrm{CH}_{3}$ \\
$(\mathrm{I})$ & 1161 & Vibrasi ulur $\mathrm{C}-\mathrm{O}$ dari ikatan antar ester \\
$(\mathrm{J})$ dan $(\mathrm{K})$ & 1118 dan 1099 & Vibrasi tekuk $-\mathrm{CH}$ dan perubahan bentuk $-\mathrm{CH}$ dari asam lemak \\
$(\mathrm{L})$ & 964 & Vibrasi tekuk gugus fungsi $\mathrm{CH}$ dari trans-olefin terisolasi \\
$(\mathrm{M})$ & 721 dan 717 & Tumpang tindih vibrasi goyangan metilen $\left(-\mathrm{CH}_{2}\right)$ dan vibrasi keluar \\
& & bidang olefin cis-disubstitusi \\
\hline
\end{tabular}

Terdapat perbedaan yang khas antara lemak sapi dan lemak tikus rumah yang terletak pada bilangan gelombang $1712 \mathrm{~cm}^{-1}(\mathrm{~F})$ dan $1377 \mathrm{~cm}^{-1}(\mathrm{H})$, bilangan gelombang puncak ini hanya terdapat dalam lemak tikus rumah sedangkan dalam lemak sapi tidak terdapat didalamnya. Pada bilangan gelombang $1712 \mathrm{~cm}^{-1}(\mathrm{~F})$ terdapat gugus fungsi karbonil $(\mathrm{C}=\mathrm{O})$ ulur asam karboksilat, dan bilangan gelombang $1377 \mathrm{~cm}^{-1}(\mathrm{H})$ menunjukkan adanya vibrasi tekuk simetris gugus metil $\left(\mathrm{CH}_{3}-\right)$. Pada bilangan gelombang $1118 \mathrm{~cm}^{-1}(\mathrm{~J})$ dan $1099 \mathrm{~cm}^{-1}(\mathrm{~K})$ menunjukkan adanya vibrasi tekuk $-\mathrm{CH}$ dan perubahan bentuk $-\mathrm{CH}$ dari asam lemak, hal ini menyebabkan lemak tikus rumah mengalami intensitas puncak yang lebih rendah bila dibandingkan dengan lemak sapi.

\section{Analisis kuantitatif dengan Partial Least Square (PLS)}

Partial Least Square (PLS) digunakan sebagai analisis kuantitatif daging tikus rumah dalam bakso daging sapi. Model kalibrasi nilai root mean square error of calibration (RMSEC) dan nilai parameter koefisien determinasi $\left(\mathrm{R}^{2}\right)$. Spektra inframerah merupakan pengukuran dari sumbu $\mathrm{X}$ dan sumbu Y. Dimana sumbu X menggambarkan bilangan gelombang (frekuensi) sedangkan pada sumbu Y menggambarkan absorbansi/transmittan (Miller, J.N., and Miller, J.C., 2005). Pada penelitian ini spektra inframerah direkam ke dalam bentuk absorbansi. Gambar 3 hubungan antara nilai aktual variasi konsentrasi dan nilai aktual yang dihasilkan instrumen spektrofotometri FTIR.

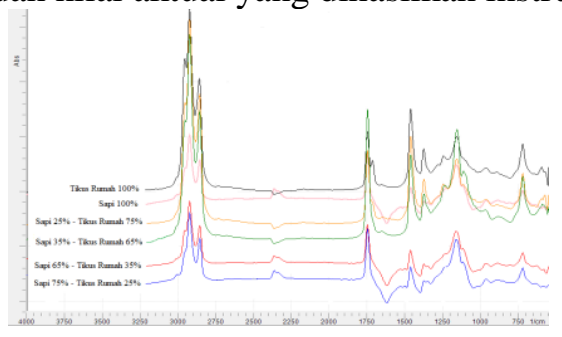

Gambar 2. Spektra FTIR lemak bakso sapi dan lemak bakso tikus rumah dengan konsentrasi tertentu $(0-100 \%)$ yang terdapat pada daerah IR tengah (4000 - 650 $\left.\mathrm{cm}^{-1}\right)$ 


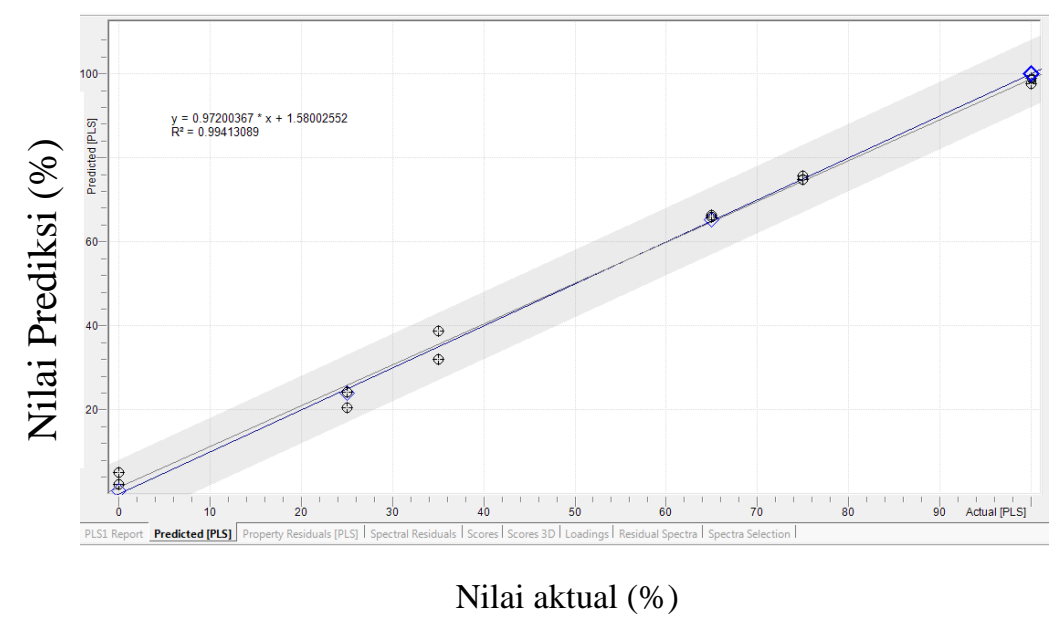

Gambar 3. Kurva hubungan antara nilai aktual lemak tikus (sumbu $x$ ) dengan nilai terprediksi (sumbu y) dengan PLS pada bilangan gelombang $1650-750 \mathrm{~cm}^{-1}$

Pada penelitian ini diperoleh model persamaan kalibrasi $\mathrm{y}=0,972 \mathrm{x}+1,580$ dengan nilai koefisien determinasi $\left(R^{2}\right)$ sebesar 0,994 . Jika nilai $R^{2}$ semakin mendekati \pm 1 , maka semakin linier hubungan antara variabel bebas dengan variabel terikat . Nilai RMSEC yang diperoleh pada penelitian ini sebesar 1,63\%, jika semakin kecil nilai RMSEC maka semakin kecil pula kesalahan yang terjadi, dan dapat dikatakan semakin valid model kalibrasi tersebut. Selain itu model validasi diperoleh nilai RMSEP sebesar 1,99 \% dan nilai RMSECV yang diperoleh sebesar 1,79\%. Nilai RMSECV dan RMSEP semakin kecil membuktikan bahwa model validasi spektrofotometri FTIR semakin baik (Miller, J.N., and Miller, J.C., 2010).

\section{Pengelompokkan dengan Principal Componen Analysis (PCA)}

PCA bertujuan untuk mengelompokkan variabel yang saling berkorelasi dan menggantinya dengan kelompok baru yang disebut dengan komponen utama (principal component) (Coltro et al., 2005; Rohman and Man, 2012). Hasil PCA pada Gambar 4 menunjukkan adanya pemisahan sempurna antara lemak tikus rumah dan lemak sapi. Hal ini menjelaskan bahwa PCA dapat mengklasifikasikan atau membedakan antara lemak celeng dan lemak sapi.

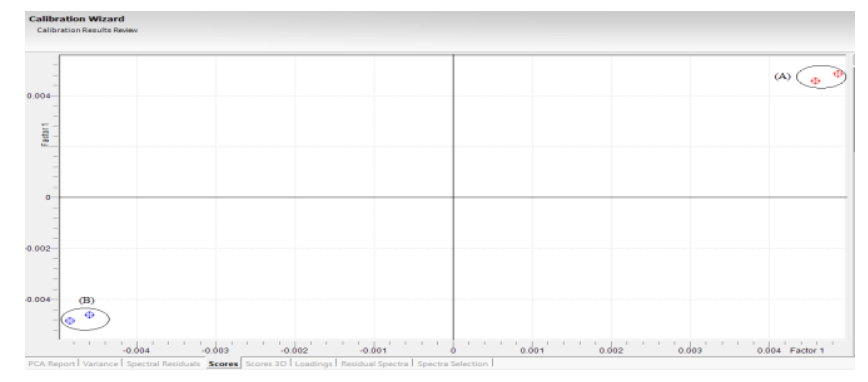

Gambar 4. Score Plot PCA untuk klasifikasi bakso daging sapi dan daging tikus rumah, kelompok (A) berwarna merah menunjukkan bakso daging sapi 100\%, kelompok (B) berwarna biru menunjukkan bakso daging tikus rumah $100 \%$

Pada Gambar 4 terlihat bahwa antara lemak sapi dan lemak tikus rumah terpisah secara sempurna dalam yang kuadran berbeda. Sehingga ini menjelaskan bahwa penggunaan metode kemometrika PCA dapat digunakan untuk mengklasifikasikan lemak sapi dan lemak tikus rumah. 


\section{Analisis sampel produk pasaran (Komersial)}

Analisis 5 sampel bakso di pasaran diambil di daerah Maguwoharjo, Yogyakarta. Gambar 5 menunjukkan pengelompokkan lemak sapi dan lemak tikus.

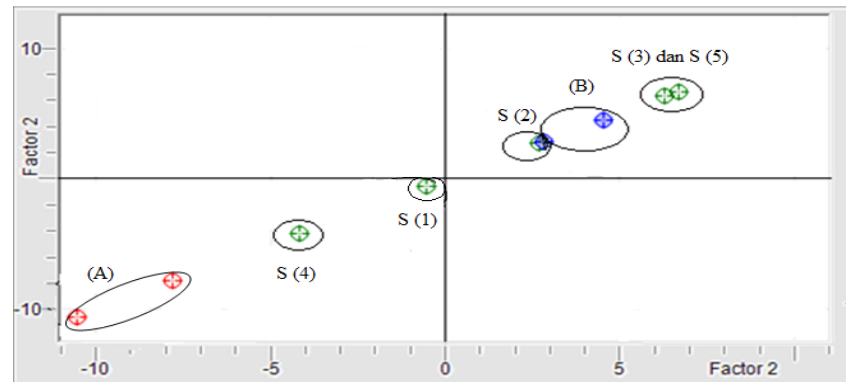

Gambar 5. Hasil Analisis PCA yang menunjukkan score plot. Warna Merah (A) menunjukkan kelompok lemak Sapi; Warna Biru (B) menunjukkan kelompok lemak Tikus Rumah; Warna Hijau (S) menunjukkan kelompok sampel yang beredar dipasaran (sampel komersial)

Pada Gambar 5, sampel pasar (1) dan sampel pasar (4) berada dalam kuadran lemak sapi. Sifat fisika kimia sampel (1) dan (4) mirip dengan lemak sapi. Sampel pasar (2), (3), dan (5) terletak pada kuadran lemak tikus. Kemungkinan lainnya adanya lemak daging lain yang digunakan dalam bakso tersebut. Sehingga dari hal ini sangat perlu dilakukan analisis dengan metode lain untuk mempertegas jenis daging yang terdapat pada sampel pasaran (2, 3 dan 5).

\section{KESIMPULAN}

Metode spektrofotometri FTIR yang dikombinasikan dengan kemometrika Partial Least Square (PLS) pada daerah bilangan gelombang 1600-750 $\mathrm{cm}^{-1}$ dapat digunakan untuk analisis kuantitatif daging tikus rumah dalam bakso sapi. Hasil model kalibrasi dengan nilai $\mathrm{R}^{2} 0,994$; RMSEC 1,63\%. Hasil model validasi diperoleh nilai RMSEP 1,99\% ; dan RMSECV 1,79\%. Metode spektrofotometri FTIR yang dikombinasikan dengan kemometrika Principal Component Analysis (PCA) mampu mengklasifikasikan lemak sapi dan tikus rumah pada bakso di pasaran.

\section{UCAPAN TERIMAKASIH}

Ucapan terima kasih kepada Lembaga Penelitian dan Pengembangan (LPP) Universitas Ahmad Dahlan, sehingga penelitian ini dapat diselesaikan.

\section{DAFTAR PUSTAKA}

Che Man, Y.B., Syahariza, Z.A., Mirghani, M.E.S., Jinap, S., and Bakar, J., 2005, Analysis of potential lard adulteration in chocolate and chocolate products using Fourier transform infrared spectroscopy. Food Chemistry, 90:815-819.

Che Man, Y.B., Syahariza, Z.A., and Rohman A., 2010, Chapter 1. Fourier Transform Infrared (FTIR) Spectroscopy: Development. Tehnique, and Application in the Analysis of Fats and Oils, in Fourier Transform Infrared Spectroscopy edited by Oliver J Ress, Nova Science Publisher, New York.

Coltro, W. K. T., Ferreira, M. M. C., Macedo, F. A. F., Oliveira, C. C., Visentainer, J. V., Souza, N. E., and Matsushita, M., 2005, Correlation of Animal Diet and Fatty Acid Content in Young Goat Meat by Gas Chromatography and Chemometrics, Meat Science, 71:358-363.

Guillén, M.D. and Cabo, N., 1997, Characterization of edible oils and lard by fourier transform infrared spectroscopy. Relationships between composition and frequency of concrete bands in the fingerprint region. Journal of the American Oil Chemists' Society, 74:1281-1286. 
Huda, N, Shen, Y.H, Huey, Y.L, Ahmad, R. dan Mardian, A, 2010, Evaluation of Physicochemical Properties of Malaysian Commercial Beef Meatball, American Journal of Food Technology, 5(1):13-21.

Julaikah, N., 2013, Harga daging sapi Indonesia salah satu yang termahal di dunia, http://www.merdeka.com/uang/harga-daging-sapi-indonesia-salah-satu-yang-termahal-didunia.html, 5 September 2014.

Maryam, S., Sismindari; Raharjo, T.J; Sudjadi; and Rohman, A., 2016, Analysis of porcine contamination in dendeng using mitochondrial D-loop 686 and cyt b gene primers by real time polymerase chain reaction. International Journal of Food Properties, 19:187-195.

Miller, J.N., and Miller, J.C., 2005, Statistics and Chemometrics for Analytical Chemistry, 4 th Edition, , Pearson Education Limited, Harlow, 232-235.

Miller, J.N., and Miller, J.C., 2010, Statistic and Chemometrics for Analytical Chemist, $6^{\text {th }}$ Edition, Pearson Education Limited, Harlow, 89-105.

Mursyidi, A., 2013, The Role of Chemical Analysis in the Halal Authentication of Food and Pharmaceutical Products. Journal of Food and Pharmaceutical Sciences, 1:76-86

Purnomo, H. and Rahardiyan, D., 2008, Review Article: Indonesian Traditional Meatball. International Food Research Journal, 15:101-108.

Rahmawati, Sismindari, Tri Joko Raharjo, Sudjadi, Abdul Rohman, 2016, Analysis of pork contamination in Abon using Mitochondrial DLoop22 Primers using Real Time Polymerase Chain Reaction Method. International Food Research Journal, 23(1):370-374.

Raraswati, M.A., Triyana, K. and Rohman, A., 2013, Differentiation of bovine and porcine gelatins in food products based on amino acid profiles and chemometrics. Journal of Food and Pharmaceutical Products, 2(1):1-6.

Rohman, A. and Che Man, Y., 2010 ${ }^{\mathrm{a}}$, FTIR spectroscopy combined with chemometrics for analysis of lard in the mixtures with body fats of lamb, cow, and chicken. International Food Research Journal, 17:519-526.

Rohman, A. and Man, Y.B.C., 2010 , Fourier transform infrared (FTIR) spectroscopy for analysis of extra virgin olive oil adulterated with palm oil. Food Research International, 43:886-892.

Rohman, A., Erwanto, Y., \& Man, Y. B. C., 2011, Analysis of pork adulteration in beef meatball using Fourier transform infrared (FTIR) spectroscopy. Meat Science, 88:91-95.

Rohman, A., Triyana, K., Sismindari, and Erwanto, Y., 2012, Differentiation of lard and other animal fats based on triacylglycerols composition and principal component analysis. International Food Research Journal, 19(2):475-479.

Schieber, A., 2008, Introduction to Food authentication. In D-W. Sun (Ed.), Modern techniques for food authentication, Elsevier Inc, New York: 1-23.

Sudjadi, H.S. Wardani, T. Sepminarti and Rohman, A., 2016, Analysis of porcine gelatin DNA in commercial capsule shell using real-time polymerase chain reaction for halal authentication. International Journal of Food Properties, 19(9):2127-2134.

Syahariza, Z.A., Man, Y.B.C., Selamat, J., and Bakar, J., 2005, Detection of lard adulteration in cake formulation by Fourier transform infrared (FTIR) spectroscopy. Food Chemistry, 92:365-371.

Van der Spiegel, M., van der Fels-Klerx, H.J., Sterrenburg, P., van Ruth, S.M., Scholtens-Toma, I.M.J., and Kok, E.J., 2012, Halal assurance in food supply chains: Verification of halal certificates using audits and laboratory analysis. Trends in Food Science \& Technology, 27:109-119. 